Departments of Gastroenterology, M Oudkerk Pool B U Ridwan

A S Peña

S G M Meuwissen

Internal Medicine, R O B Gans

Pathology,

B M E von Blomberg H Bril

and Medical Statistics, Free University Hospital Amsterdam, Amsterdam, Netherlands

J J Nauta

Department of Gastroenterology, St Elisabeth Gasthuis

Haarlem

W Dekker

Department of

Haematology, Academic

Medical Centre, and

Central Laboratory of the

Netherlands Red Cross

Blood Transfusion

Service, Amsterdam, The

Netherlands

P M Ellerbroek

R Goldschmeding

K M Dolman

Department of Internal Medicine, St Jans Gasthuis, Weert

H Breed

Correspondence to: Professor

S G M Meuwissen, Dept of

Gastroenterology, Fre

University Hospital, de

Boelelaan 1117, 1081 HV

Amsterdam, The

Netherlands.

Accepted for publication

8 June 1992

\title{
Serum antineutrophil cytoplasmic autoantibodies in inflammatory bowel disease are mainly associated with ulcerative colitis. A correlation study between perinuclear antineutrophil cytoplasmic autoantibodies and clinical parameters, medical, and surgical treatment
}

M Oudkerk Pool, P M Ellerbroek, B U Ridwan, R Goldschmeding, B M E von Blomberg, A S Peña, K M Dolman, H Bril, W Dekker, J J Nauta, R O B Gans, H Breed, S G M Meuwissen

\section{Abstract}

Perinuclear antineutrophil cytoplasmic antibodies have recently been demonstrated in the sera of patients with inflammatory bowel disease. Three hundred and sixty six sera obtained from 120 patients with ulcerative colitis, 105 patients suffering from Crohn's disease and 49 non-inflammatory bowel disease controls were tested in two laboratories, using an indirect immunofluorescence assay. In addition, a fixed-neutrophil enzyme linked immunoadsorbent assay (ELISA) was evaluated in one of the two laboratories. The results in the immunofluorescence test showed a high degree of correlation between the two laboratories (Kappa coefficient $=0 \cdot 8$ ). Ninety five of the $120(79 \%)$ ulcerative colitis patients had a positive test whereas only 14 of the 105 (13\%) patients with Crohn's disease were positive. Sera from four patients suffering from primary sclerosing cholangitis were positive as well as four of the $\mathbf{4 5}$ control sera (9\%). The sensitivity of the perinuclear antineutrophil cytoplasmic antibody immunofluorescence test for the diagnosis of ulcerative colitis was 0.75 with a specificity of 0.88 and a positive predictive value of 0.88 (all sera). In the ELISA technique 37 of 94 ulcerative colitis sera and one of the 68 Crohn's disease sera were positive. In the control group only one of the patients suffering from primary sclerosing cholangitis reacted positively ( 32 non-inflammatory bowel disease sera tested). The ELISA technique had a high specificity $(0.97)$, but a low sensitivity (0.39). There was no relation of perinuclear antineutrophil cytoplasmic antibodies in ulcerative colitis patients or in Crohn's disease patients with disease activity, duration of illness, localisation, extent of disease, previous bowel operations or medical treatment. The clinical significance of perinuclear antineutrophil cytoplasmic antibody positive and negative subsets in both groups of patients thus remains unexplained. Our study confirms that determination of serum anti- neutrophil cytoplasmatic antibodies in patients with inflammatory bowel disease may differentiate ulcerative colitis from Crohn's disease. Further immunological studies are needed to explain the absence of these antibodies in a subset of ulcerative colitis patients and their role in the pathogenesis of the disease.

(Gut 1993; 34: 46-50)

Ulcerative colitis and Crohn's disease belong to the group of idiopathic inflammatory bowel diseases and could theoretically be extremes of

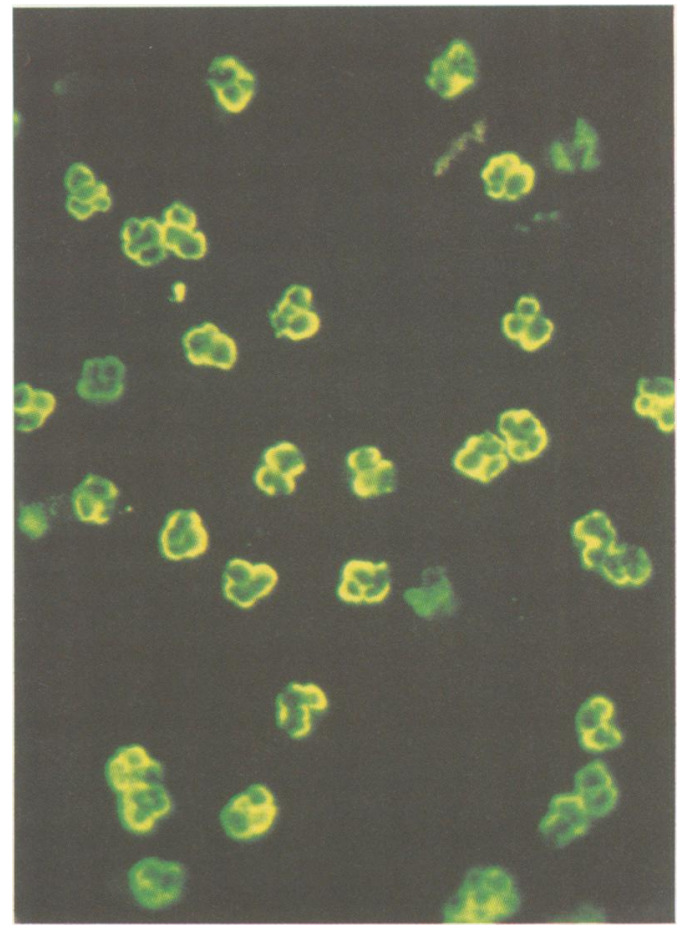

Figure 1: Immunofluorescence perinuclear binding pattern in serum from a patient with ulcerative colitis. 
the same disease. It is more likely, however, that they are fundamentally different. With regard to the diagnosis in approximately $10 \%$ of inflammatory bowel disease patients with colonic involvement a definite distinction cannot be made. ${ }^{12}$ Antineutrophil cytoplasmic antibodies are used in diagnosing vasculitic diseases. In these diseases the related antigens are enzymes in the granules of neutrophils. ${ }^{3-5}$ Also in patients with inflammatory bowel disease antineutrophil cytoplasmic antibodies have been detected. The fluorescence pattern of inflammatory bowel disease associated antineutrophil cytoplasmic antibodies is characteristically perinuclear (Fig 1). It has been agreed to call these antibodies perinuclear antineutrophil cytoplasmic antibodies to differentiate them from the classical cANCA present in Wegener's granulomatosis. Saxon et al reported that IgG perinuclear antineutrophil cytoplasmic antibodies could be detected in the sera of the majority of patients with ulcerative colitis and in a much smaller percentage of the sera of patients with Crohn's disease. ${ }^{6}$ We showed equivalent results in a large group of European patients $(n=274)$ using an indirect immunofluorescent technique. ${ }^{7}$ In the present study we have determined the sensitivity and specificity of antineutrophil cytoplasmic antibodies as measured either by immunofluorescence or fixed neutrophil ELISA tests. In addition, we have investigated the possible relation of the presence or absence of these antibodies with clinical and biochemical parameters, disease activity and extent of disease, and medical or surgical treatment.

\section{Methods}

\section{STUDY POPULATION AND SERUM SPECIMENS}

Three hundred and sixty six serum samples were obtained from 274 unrelated patients attending the departments of Gastroenterology and Internal Medicine over a nine month period. The diagnosis of ulcerative colitis or Crohn's disease was based on conventional clinicopathologic criteria according to those described by LennardJones et al. ${ }^{8} \mathrm{We}$ excluded 12 patients because no definite diagnosis of ulcerative colitis or Crohn's disease could be made at the time of testing. Sera from patients positive for antinuclear antibodies were also excluded (15\% in ulcerative colitis; $8.5 \%$ in Crohn's disease). One hundred and twenty ulcerative colitis patients, 105 Crohn's disease patients and 49 controls were studied. The mean age was 40 years, an equal male/female distribution was found. Control subjects were patients from the same outpatient clinics, matched for sex and age to the inflammatory bowel disease patients without evidence of inflammatory bowel disease. In this particular control group nine patients suffered from diarrhoea, 15 patients had spastic colon, 10 suffered from gastritis, one patient had Wegener's granulomatosis, in 10 patients we diagnosed diverticulosis and five had carcinoma of different origin.

The disease activity in Crohn's disease was assessed using the CDAI according to Best et $a l^{9}$ and van Hees $e t a l^{10}$ and in ulcerative colitis the
Sutherland score was used." The patient's disease activity ranged from mild to severe at the time of serum collection. In ulcerative colitis, 114 patients scored $0-3,33$ scored $4-7,16$ scored $8-10$, and nine patients over 10 at the time of serum collection $(0=$ quiet; $12=$ very severe disease activity). All sera were stored at $-20^{\circ} \mathrm{C}$ until assay. Perinuclear antineutrophil cytoplasmic antibody screening was performed in a blind prospective transversal setting. One hundred and seventy two serum samples from 120 patients suffering from ulcerative colitis, 145 from 105 Crohn's disease patients, and 49 control sera were tested in two laboratories. From 84 patients ( 37 suffering from ulcerative colitis and 47 from Crohn's disease) sera were collected at different timepoints for follow up of antineutrophil cytoplasmic antibody reactivity in relation to clinical parameters.

\section{INDIRECT IMMUNOFLUORESCENCE ASSAY}

The standard antineutrophil cytoplasmic antibodies indirect immunofluorescence assay ${ }^{12}$ was performed in two laboratories (Central Laboratory of the Netherlands Red Cross Blood Transfusion Service and Immunohaematological Laboratory of the Free University Hospital). In short, human peripheral blood neutrophils were smeared on eight well Nutacon slides and fixed in $96 \%$ ethanol ( 15 minutes $4^{\circ} \mathrm{C}$ ). Slides were incubated with 1:16 diluted patient's sera and stained with fluorescein conjugated rabbit antihuman IgG antibodies. The slides were evaluated by fluorescence microscopy. Depending on brightness of immunofluorescence staining pattern, the reactions were graded into negative $(-)$, weak $(+)$, positive $(++)$, and strong positive $(+++)$.

\section{FIXED NEUTROPHIL ELISA TECHNIQUE}

According to the technique described by Saxon et $a l^{6}$ microtitre plates were coated with a monolayer of granulocytes, fixed in methanol, and air dried. Sera were tested at a 1:40 dilution and bound antibody was detected with alkaline phosphatase conjugated goat antihuman gamma chain specific antibody. $3 \mathrm{SD}$ above the mean of the negative controls was considered positive.

\section{STATISTICAL ANALYSIS}

To measure interobserver variation of indirect immunofluorescence testing of the 366 sera Cohen's kappa coefficient was used. Kappa coefficients above 0.75 signify excellent agreement. ${ }^{13}$ Sensitivity was defined as the ratio of true

Comparison of results obtained by ELISA or indirect immunofluorescence assay in 94 ulcerative colitis and 68 Crohn's disease patients

\begin{tabular}{lcl} 
& ELISA $(n)$ & ELISA $(n)$ \\
\hline Ulcerative colitis & + & - \\
IFA (n) + & 31 & 31 \\
IFA (n) - & 6 & 26 \\
Crohn's disease & + & - \\
IFA (n) + & 1 & 4 \\
IFA (n) - & 0 & 63 \\
\hline
\end{tabular}

$\mathrm{n}=$ Number of patients. 


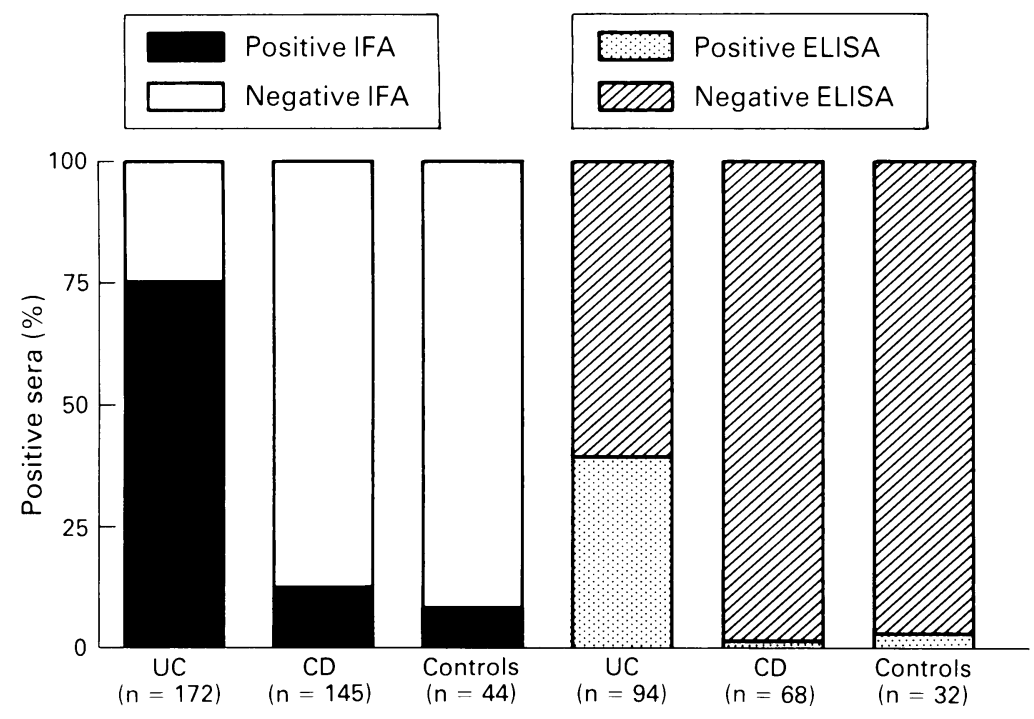

Figure 2: Perinuclear antineutrophil cytoplasmic antibody ( $p A N C A)$ reactivity of sera from ulcerative colitis $(U C)$ patients, Crohn's disease (CD) patients and normal controls with indirect immunofluorescence assay immunoftuorescence assay
(left) versus their binding in the fixed whole cell ELISA (right).

Figure 3: Perinuclear antineutrophil cytoplasmic antibody $(p A N C A)$ reactivity in 172 sera from ulcerative colitis ( $U C$ ) patients in relation to the disease activity. positives to true positives plus false negatives; specificity as that of true negatives to true negatives plus false positives; positive predictive value as that of true positives to true positives and false positives, and negative predictive value as that of true negatives to true negatives plus false negatives. ${ }^{1+}$ To measure associations, Pearson's correlation coefficient was used.

\section{Results}

INTERLABORATORY CORRELATION OF THE PERINUCLEAR ANTINEUTROPHIL CYTOPLASMIC ANTIBODY IMMUNOFLUORESCENCE TEST

The same immunofluorescence test procedure for the determination of perinuclear antineutrophil cytoplasmic antibodies in the serum of patients and controls was followed in two independent laboratories. Reproducability in these laboratories showed an interlaboratory variation maximal up to $14 \%$ (177 sera perinuclear antineutrophil cytoplasmic antibody positive, 129 sera perinuclear antineutrophil cytoplasmic antibody negative in both laboratories; 48 sera different scored), thus excellent agreement was shown (kappa score $0 \cdot 80$ ). ${ }^{1}$

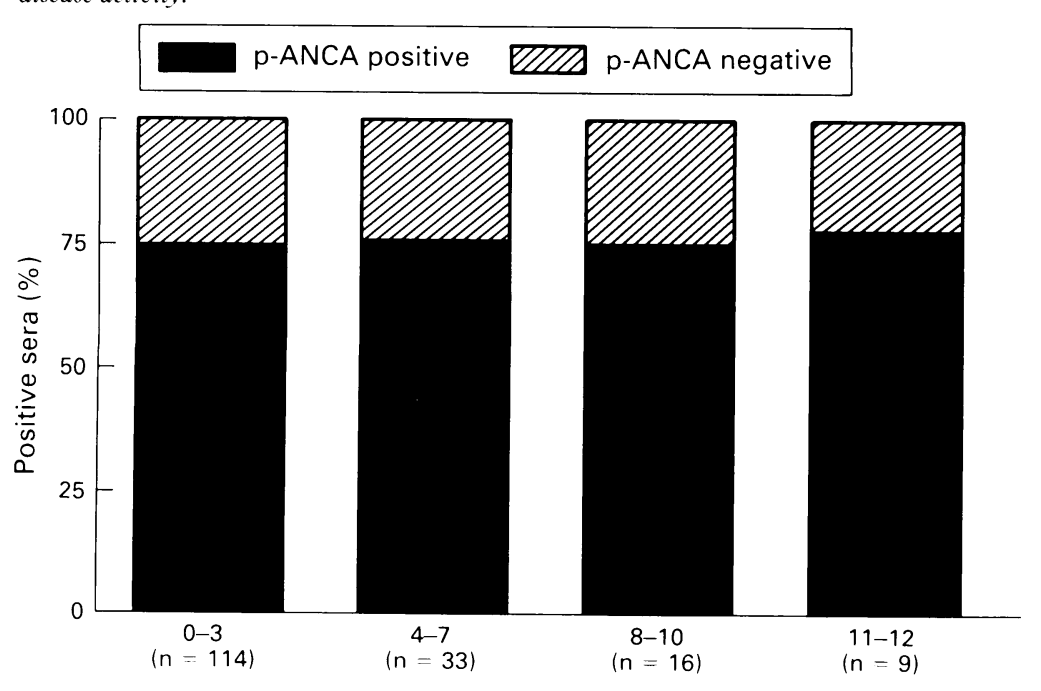

Sutherland score

COMPARISON OF PERINUCLEAR ANTINEUTROPHIL CYTOPLASMIC ANTIBODY MEASUREMENTS BY INDIRECT IMMUNOFLUORESCENCE ASSAY AND ELISA AND THEIR VALUE IN THE DIFFERENTIAL. DIAGNOSIS OF INFLAMMATORY BOWEL DISEASE In the indirect immunofluorescence assay method the sensitivity of perinuclear antineutrophil cytoplasmic antibodies for ulcerative colitis was 0.75 and the specificity 0.88 ; using the ELISA technique our figures were 0.39 and 0.97 respectively (Fig 2). For ulcerative colitis, the positive predictive value of a positive perinuclear antineutrophil cytoplasmic antibody test in the indirect immunofluorescence assay was 0.88 , the negative predictive value of a negative perinuclear antineutrophil cytoplasmic antibody test was $0 \cdot 75$.

The Table gives the exact correlation between ELISA and indirect immunofluorescence assay results in the ELISA tested subgroup. Only 14 out of 105 Crohn's disease patients showed perinuclear antineutrophil cytoplasmic antibody reactivity by indirect immunofluorescence assay. In the ELISA technique only one of 68 Crohn's disease patients was positive for perinuclear antineutrophil cytoplasmic antibodies. In contrast, sera from all patients suffering from primary sclerosing cholangitis show a bright $3+$ staining in the indirect immunofluorescence assay.

The ELISA technique proved far less sensitive for identification of ulcerative colitis patients in inflammatory bowel disease but showed a higher specificity than did the indirect immunofluorescence assay.

\section{RELATIONSHIP OF PERINUCLEAR}

ANTINEUTROPHIL CYTOPLASMIC ANTIBODIES WITH DISEASE ACTIVITY, HAEMATOLOGICAL, BIOCHEMICAL PARAMETERS, EXTENT, ANI) EFFECT OF TREATMENT IN ULCERATIVE COLITIS

Disease activity was assessed in 120 ulcerative colitis patients based on the criteria as outlined by Sutherland et al. In a longitudinal study of 37 patients a significant difference in activity index before and after treatment was observed, irrespective of the kind of treatment - for example, corticosteroids, 5 ASA, SASP, or surgery. The activity index ranging from $0-12$ decreased 3.2 points on average $(p=0.0046$, Student's $t$ test for paired observations). No significant relationship was found between positivity of perinuclear antineutrophil cytoplasmic antibodies and ulcerative colitis activity. Furthermore, all patients that were perinuclear antineutrophil cytoplasmic antibody positive before treatment remained positive after treatment, and no apparent decrease in staining intensity was noted.

A positive correlation was found between disease activity and the number of peripheral blood leucocytes $(r=0 \cdot 44 ; p<0 \cdot 001)$. A significant negative correlation was observed between disease activity and hacmatological and biochemical parameters, in particular haemoglobin $(\mathrm{r}=-0.271 ; \mathrm{p}=0.004)$, serum albumin $(\mathrm{r}=$ $-0.486 ; \mathrm{p}<0.001)$ and total serum protein $(\mathrm{r}=-0.450 ; \mathrm{p}<0.001)$. These haematological and biochemical parameters, however, were not 
related to the presence of perinuclear antineutrophil cytoplasmic antibody reactivity, except for a negative correlation between the presence of perinuclear antineutrophil cytoplasmic antibodies and serum albumin concentration $(\mathrm{r}=-0 \cdot 215 ; \mathrm{p}=0.031)$.

No difference in fluorescence intensity level (1-3) nor difference in percentage of perinuclear antineutrophil cytoplasmic antibody positive patients among patients suffering from proctitis $(n=13)$, proctosigmoiditis $(n=56)$, and pancolitis $(n=38)$ was found.

In patients with ulcerative colitis who underwent a total (nine) or subtotal (five) colectomy the percentage of perinuclear antineutrophil cytoplasmic antibody positivity remained unchanged regardless of the time passed after colectomy (maximum duration of follow up was over 20 years).

\section{Discussion}

It has been shown that the perinuclear antineutrophil cytoplasmic antibody indirect immunofluorescence test may help to differentiate between Crohn's disease and ulcerative colitis in inflammatory bowel disease patients. ${ }^{671516}$ In a large blinded study done in two independent laboratories we confirmed the presence of perinuclear antineutrophil cytoplasmic antibodies by the indirect immunofluorescence test in $79 \%$ of ulcerative colitis patients whereas only $13 \%$ of Crohn's disease patients and $9 \%$ of the control group were positive (means from two laboratories).

In contrast with the results of Saxon et al $l^{6}$ our indirect immunofluorescence assay results showed greater sensitivity and a similar specificity compared with the ELISA test. The indirect immunofluorescence assay is suitable for clinical investigation of patients with inflammatory bowel disease: results are reproducible and correlate well in independent laboratories. Our results confirm the presence of a perinuclear antineutrophil cytoplasmic antibody negative subgroup of ulcerative colitis patients. These patients often had clinically, endoscopically, and histologically active disease. They were indistinguishable from perinuclear antineutrophil cytoplasmic antibody positive ulcerative colitis patients (Fig 3 ).

No satisfactory explanation can be given as to why our ELISA results differ from Saxon et al. It is unlikely that the methodology is responsible, because a similar protocol was used. Although we used +3 SD above the mean of negative controls as cut off level for positivity in comparison to the +2 SD used by Saxon et al this alone cannot explain the differences. The different source of the neutrophils used in the assay may result in the recognition of different antigens, although Saxon et al showed no significant difference in binding with the neutrophils taken from eight normal subjects. The use of a different (European) donor pool can account for the difference.

No correlation was found between perinuclear antineutrophil cytoplasmic antibody positivity and localisation or extent of ulcerative colitis. In contrast with the close relationship of levels of vasculitis associated antineutrophil cytoplasmic antibodies, no correlation was observed between perinuclear antineutrophil cytoplasmic antibody level and disease activity in inflammatory bowel disease. (Procto-) colectomy did not result in disappearance of perinuclear antineutrophil cytoplasmic antibodies, during a follow up period ranging between two months and two years (mean nine months). Antibodies could still be demonstrated in one patient 20 years after a proctocolectomy.

The reaction of perinuclear antineutrophil cytoplasmic antibody titre to medication (corticosteroids or mesalazine) is controversial. Disappearance of perinuclear antineutrophil cytoplasmic antibodies after treatment with corticosteroids has been reported in a small number of patients. ${ }^{15} 16$ In a group of 37 ulcerative colitis patients, however, no effect of medication was found.

The pathophysiological importance of the ulcerative colitis associated perinuclear antineutrophil cytoplasmic antibodies is still poorly understood. Evidence has accumulated that several autoimmune phenomena are present in ulcerative colitis patients. ${ }^{17}$ Possibly, HLA heterogeneity or the presence of other not yet identified immunogenetic markers may be responsible for the existence of a perinuclear antineutrophil cytoplasmic antibody positive and negative subgroup in ulcerative colitis. The presence of perinuclear antineutrophil cytoplasmic antibodies in unaffected family members of ulcerative colitis patients favours this view. ${ }^{18}$ Of particular interest is the observation that primary sclerosing cholangitis patients are also perinuclear antineutrophil cytoplasmic antibody positive. ${ }^{19}$ Possibly, ulcerative colitis and primary sclerosing cholangitis associated neutrophil cytoplasmic antibodies recognise the same antigen(s).

In the past, autoantibodies that have been most consistently detected in inflammatory bowel disease are those reactive to colonic cells and lymphocytes. ${ }^{61520-26}$ In our study autoantibodies detected in ulcerative colitis are not only directed towards neutrophils, but also to a very small percentage of monocytes (Ellerbroek et al; submitted). No reaction with the antigen(s) recognised by vasculitis associated antineutrophil cytoplasmic antibodies - that is myeloperoxidase, elastase, or proteinase 3 , could be demonstrated. ${ }^{67} 1527$

In conclusion, our study confirms that perinuclear antineutrophil cytoplasmic antibodies are indeed demonstrable in the large majority of ulcerative colitis patients. Therefore, antibody determination may have a place in the clinical decision making of inflammatory bowel disease patients, since positivity provides strong arguments for the diagnosis of ulcerative colitis.

Presented as a poster at the New Orleans Meeting of the American Gastroenterology Association, May 1991, New Orleans.

1 Tedesco FJ. Differential diagnosis of ulcerative colitis and Crohn's ileocolitis and other specific inflammatory diesases of the bowel. Med Clin North Am 1980; 64: 1173-88.

2 Shanahan F, Targan SR. Immunology of inflammatory bowel disease. In: Schaffer E, Thomson ABR, eds. Modern concepts in gastroenterology. Vol 2. Plenum Publishing, 1989.

3 Falk RJ, Jennette JC. Anti-neutrophil cytoplasmic auto- 
antibodies with specificity for myeloperoxidase in patients with systemic vasculitis and idiopathic necrotizing and crescentic glomerulonephritis. $N$ Engl f Med 1988; 318 : $1651-7$.

4 Ludemann J, Utrecht B, Gross WL. Anti-neutrophil cytoplasm antibodies in Wegener's granulomatosis recognize an elastinolytic enzyme. $\mathcal{J}$ Exp Med 1990; 171: 35762.

5 Goldschmeding R, vd Schoot CE, ten Bokkel Huinink D Hach CE, van den Ende ME, Kallenberg CGM, et al. Wegener's granulomatosis autoantibodies identify a novel diisopropyl granulomatosis autoantibodies identify a novel some of normal human neutrophils. F Clin Invest 1989; 84: some of nort

6 Saxon A, Shanahan F, Landers C, Ganz T, Targan SR. A distinct subset of antineutrophil cytoplasmic antibodies is associated with inflammatory bowel disease. $\mathcal{F}$ Allergy Clin mmunol 1990; 86: 202-10.

7 Oudkerk Pool M, Ellerbroek PM, Goldschmeding R, Blomberg BME, Dolman KM, Dekker W, et al. Serum antineutrophil autoantibodies in patients with inflammatory bowel disease: localization studies of the related antigen(s). Gastroenterology 1991; 100: A236.

8 Lennard-Jones JE. Classification of inflammatory bowe disease. Scand F Gastroenterol 1989; 24 (suppl 170): 2-6.

9 Best WR, Becktel JM, Singleton JW. Rederived values of the eight coefficients of the Crohn's disease activity index (CDAI). Gastroenterology 1979; 77: 843-6.

10 van Hees PAM, van Elteren PH, van Lier HJJ, van Tongeren JHM. An index of inflammatory activity in patients with Crohn's disease. Gut 1980; 21: 279-86.

11 Sutherland LR, Martin F, Greer S, Robinson M, Greenberger $\mathrm{N}$, Saibil F, et al. 5-Aminosalicylic acid enema in the $\mathrm{N}$, Saibil F, et al. 5-Aminosalicylic acid enema in the treatment of distal ulcerative colitis, proctosig

proctitis. Gastroenterology 1987; $92: 1894-8$.
12 Wiik A. Detection of a standard procedure for indirect immunofluorescence detection of ANCA. APMIS 1989; 97 $12-5$

13 Fleiss JL. Statistical methods for rates and proportions. 2nd ed. New York: John Wiley, 1981: 211-36.

14 Fletcher RH, Fletcher SW, Wagner EH. Clinical epidemiology, the essentials. 2nd ed. Baltimore: Williams \& Wilkins, 1988 42-75.

15 Rump JA, Schölmerich J, Gross V, Roth M, Helfesrieder R, Rautmann $\mathrm{A}$, et al. A new type of perinuclear anti- neutrophil cytoplasmic antibody (p-ANCA) in active ulcerative colitis but not in Crohn's disease. Immunobiology 1990; 181: 406-13.

16 Roth M, Rump JA, Gross WL, Peter HM, Geroh W, Schölmerich J, et al. A new type of anti-neutrophil antibodies in sera from patients with ulcerative colitis but not Crohn's disease. Gastroenterology 1991; 100: A244.

17 Oldstone MBA. Molecular mimicry and autoimmune disease. Cell 1987; 50: 819-20.

18 Shanahan F, Duerr R, Rotter JI, Yang $H$, Sutherland LR, Mc Elree C, et al. Neutrophil autoantibodies in ulcerative colitis: familial aggregation and genetic heterogeneity. Colitis: familial aggregation and

19 Duerr RH, Targan SR, Landers CJ, Larusso NF, Lindsay $\mathrm{KL}$, Wiesner RH, et al. Neutrophil cytoplasmic antibodies: a link between primary sclerosing cholangitis and ulcerative colitis. Gastroenterology 1991; 100: 1385-91.

20 Fiocchi C, Roche JK, Michener WM. High prevalence of antibodies to intestinal epithelial antigens in patients with inflammatory bowel disease and their relatives. Ann Intern Med 1989; 110: 786-94.

21 Roth MP, Peterson GM, Mc Elree C, Panish JF, Rotter JI, et al. Familial risk estimates of inflammatory bowel diseases in Ashkenazi Jews. Gastroenterology 1989; 96: 1016-20.

22 Snook JA, Chapman RW, Fleming K, Jewell DP. Antineutrophil nuclear antibody in ulcerative colitis, Crohn's disease and primary sclerosing cholangitis. Clin Exp Immunol 1989; 76: 30-3.

23 Korsmeyer SJ, Williams RG, Wilson ID, Strickland RG. Lymphocytotoxic antibody in inflammatory bowel disease. NEnglf Med 1975; 293: 1117-20.

24 Broberger O, Perlman P. Autoantibodies in ulcerative colitis. f Exp Med 1959; 110: 657-74.

25 Das KM, Vecchi M, Sakamaki S. A shared and unique epitope(s) on human colon, skin and biliary epithelium detected by a monoclonal antibody. Gastroenterology 1990 98: 464-9.

26 Takahasi F, Das KM. Isolation and characterization of a colonic autoantigen specifically recognized by colon tissuebound immunoglobulin $\mathrm{G}$ from idiopathic ulcerative colitis. f Clin Invest 1985; 76: 311-8.

27 Duerr RH, Targan SR, Landers CJ, Sutherland LR, Shanahan F, et al. Anti-neutrophil cytoplasmic antibodies in ulcerative colitis: comparison with other colitides/diarrhea/ illnesses. Gastroenterology 1991; 100: 1590-6 